\title{
Research on the Effectiveness of Management Accounting in China: Perspectives from the Interaction of Formal and Informal Control
}

\author{
Xiangfei Zeng ${ }^{1,2}$, Lianghua Chen ${ }^{1}$ \\ ${ }^{1}$ School of Economics and Management, Southeast University, Nanjing, China; \\ ${ }^{2}$ School of Business, Anhui University of Technology, Ma`an Shan, China
}

\begin{abstract}
The control means of management accounting in practice does not work as effectively as that in theory, for the reason that the importance of informal control is overlooked. Based on the empirical data of listed high-tech companies in China, this paper analyzes different matching types between the formal and informal control and the relative effects on the enterprise performance. The findings of this study offer a broader way to improve the enterprise performance and enrich the research contents of management accounting. At the same time, it can also attach great importance to the matching type of management accounting control in practice.
\end{abstract}

Keywords: management accounting, formal control, informal control, organizational performance

\section{Introduction}

The management accounting neglects the invisible informal control while pays attention to the explicit formal control is not good for the development of management accounting in China. China's Ministry of Finance promulgated the "Guidance to comprehensively promote the management accounting system (Exposure Draft)" in 2014 and the "Management Accounting Basic Guidelines" in 2016. It is noteworthy that we should not only pay attention to the effect of formal control, but also to the role of informal control when formulating all kinds of specific guidelines. Okamoto K (2009) [1] pointed out that if the enterprise only focuses on the formal elements of management control and ignore the informal elements, management control would lose the soul and characteristics. Both of the "Statements on Management Accounting" published by IMA(Institute of Management Accountants) in 2010 and the "Global Management Accounting Principles" issued by CIMA and AICPA in 2014 described the management accounting tools in the comprehensive and detailed way. However, the expressions of these statements had been criticized by many scholars: management accounting tools only focused on the matching problem of elements and dimensions of formal control (such as specialization, scale, standardization, etc.) [2], and neglecting the role of informal control [3]. We also investigate the practice of well-known management accounting tools which draw significant attention of the literature and the media, for example, the Activity-Based Costing, Activity-Based Management (ABC/ABM), Target Cost Management (TCM), Cost Design , Balanced Scorecard (BSC) and other tools. Their practical effects cannot match the academic praise [4], for the reason that the practical effect of management accounting not only depends on the explicit formal control, but also depends on the role of recessive informal control. During the process of construction and promotion of management accounting standards in China, people have the tendency to ignore the existence and the effect of informal control. It is not conducive to the construction and development of Chinese management accounting.

Based on the analysis above, this paper takes listed high-tech companies in China from 2012 to 2015 as the research objects to study the relationship between formal and informal control in management accounting. We 
try to answer: (1) What is the relationship between informal and formal control in management accounting? (2) If different matching types of formal and informal controls have different impacts on firm performance?

The contributions of this paper are as follows: (1) Reveal the relationship between the formal control and informal control in theory. (2) Emphasize different matching types of formal and informal controls in the guidelines and norms of management accounting for government in practice. The remainders of this paper are organized as follows: Section 2 presents theoretical analysis and research assumptions. Section 3 presents the research design. Then the empirical result is analyzed in Section 4. Section 5 presents the conclusions.

\section{Theoretical Analysis and Research Assumptions}

Management accounting is composed of formal control and informal control. Management accounting benefits from the matching type of different forms of control. If there was an imbalance in the match, it may lead to ambiguous information. It made us confused and lost. The effect of management accounting was destroyed [5-6]. We define the complementary matching categories according to the different functions of formal and informal control to further verify them. We try to provide more detailed analysis tools for exploring the complementary matching problem of formal and informal control.

Management accounting has two roles for using. On one hand is to achieve organizational goals by management implements control, the other is to seek opportunities and solve problems by the staff. Management accounting had both executive and adaptive capabilities. [7] In the previous studies, the classification for the concept of matching mainly gathers around Muchinsky and Monahan's (1987) point of view [8]. They proposed the supplementary match and complementary match. The supplementary match means that one side could be added, modified or had similar characteristics as the other side through the organizational behavior. They changed in the same direction. The complementary match means that one side could be complementary with the other side on characteristic through the organizational behavior. The directions of changes are inconsistent. This research agrees that the Matching Theory of the supplementary match and complementary match in management accounting controls. Because of the direction of their change, the interaction between formal and informal control shows different types.

According to the two points of view above, we propose four kinds of "matching types" between management accounting control. We believe that the management accounting control tools maybe the one of four matching ways or they may be start with one type then continually circulate. We plot the matching paths of the two controls on the axis (Figure 1).The $\mathrm{X}(\mathrm{Y})$ axis shows that the two control activities mixed of execution capacity and adaptive capacity function types. The left end of the $\mathrm{X}$-axis (the lower end of the $\mathrm{Y}$-axis) corresponds to the activity that focuses on adaptability. The right end of the $\mathrm{X}$-axis (the upper end of the $\mathrm{Y}$-axis) indicates the activity focused on execution. Four quadrants are used to represent the formal and informal controls matching types. The first and third quadrants show that the direction of formal and informal control carried out by managers are the same . The formal and informal controls emphasize the executive capacity for the purpose of the activity. It can produce the single income effect of management accounting (supplementary match).The fourth quadrant indicates that the direction of formal and informal control which the managers implement are different. Two of the controls emphasize the executive capacity or adaptive capacity respectively for the purpose of the activity. It can produce the dual income effect of management accounting (complementary match). 


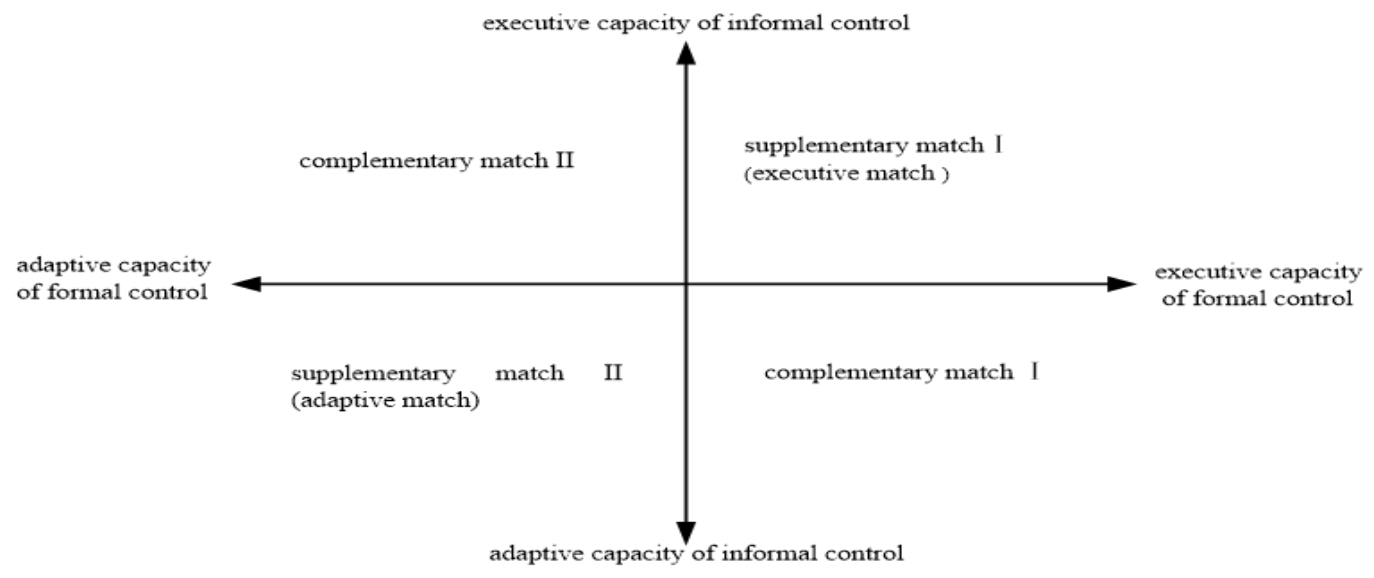

Fig. 1: matching paths of the two controls on the axis

In summary, we propose hypothesis:

H1: The complementary match I of the formal and informal control is conducive to enhancing firm performance.

$\mathrm{H} 2$ : The complementary match II of the formal and informal control is conducive to enhancing firm performance.

H3: The supplementary match I of the formal and informal control (executive matching) is conducive to enhancing firm performance.

H4: The supplementary match II of the formal and informal control (adaptive matching) is conducive to enhancing firm performance.

\subsection{Model Setting and Variable Definition}

In order to verify the interaction between informal control and formal control, we adopt the multiple regression analysis method to analyze the relationship between formal and informal control by judging their regression coefficients. To test Hypothesis 1-4, we set the following research model(1):

$$
\mathrm{ROA}_{\mathrm{i}, t}=\gamma_{0}+\gamma_{1} I C_{\mathrm{i}, t-1}+\gamma_{2} F C_{i, t-1}+\gamma_{3} I C_{i, t-1} * F C_{i, t-1}+\gamma_{4} \text { Control }_{i, t}+\varepsilon
$$

This report selects the part of board in companies' annual report as the analysis objects and uses the text analysis software ROSTCM6 to measure the intensity of "formal control" and "informal control" of each enterprise. Firstly, we follow the recommendations of UOTILA (2009) [9] and identify the key words of "formal control" and "informal control" according to the definitions in some authority literatures. The keywords of Formal control include rule, system, budget, performance evaluation, incentive and management accounting technology. Informal control keywords include idea, corporate culture, values, mission, and social responsibility. We add four variables--executive capacity of formal control (FCa), adaptive capacity of formal control (FCb ), executive capacity of informal control(ICc) and adaptive capacity of formal control (ICd))to the independent variables. Through the text analysis of management accounting and the keyword context, we subjectively judge the classification for formal and informal control tools between the executive capacity and adaptive capacity. Further, the firm's intensity of these variables are quantified and measured again. For example: we investigate the keyword "budget". If it is found to emphasize the rigidity implementation, we will define it as "FCa". We also define it as "FCb" if the content emphasis on the flexibility of the budget adjustment and reflects the adaptive capacity. And so on. 
These keywords are discussed and revised by expert groups (composed of 2 professors in management accounting and 6 entrepreneurs). All the keywords are with high reliability and validity and cluster into two categories as "formal control" and "informal control". Secondly, we quantified "formal control" and "informal control" according to the category system. Taking the inconsistency in the length of the report of the Board of Directors into account, we divided words frequency of "formal control" and "informal control" by the total length of the Board of Directors report. Finally, the strength of the above variables measuring results is obtained.

The control variables Following the study of Sun (2003) [10] and Xiao Zezhong and Du Rongrui (2009) [11], we chose some variables as the control variables: SIZE is the natural logarithm of total assets, AGE is firm age, SOE is State-owned enterprise, RD is R\&D intensity of firm and LEV is total liabilities divided by total assets. Because there exists the time lag for the impact of management accounting on performance of firms, we select current period data of the independent variables and control variables. The dependent variable lags one period. Besides the above variables, we also include year-dummies and industry-dummies to control year effects and industry effects. The specific definitions of the relevant indicator are shown in Table I:

TABLE I: Formal and Informal Control of Different Types of Match

\begin{tabular}{llll}
\hline \hline type & Variables & Acronym & Definition \\
\hline $\begin{array}{l}\text { Dependent variable } \\
\text { Independent variable }\end{array}$ & $\begin{array}{l}\text { Firm Performance } \\
\text { Formal control }\end{array}$ & ROA & $\begin{array}{l}\text { Net income divided by year-end total assets } \\
\text { Firm in the year of formal control strength }\end{array}$ \\
& FC & Informal control & Firm in the year of informal control strength \\
Control variables & $\begin{array}{l}\text { Leverage ratio } \\
\text { Firm size } \\
\text { R \& D intensity of firm }\end{array}$ & $\begin{array}{l}\text { LEV } \\
\text { SIZE }\end{array}$ & $\begin{array}{l}\text { Year-end total liability divided by year-end total assets } \square \square \\
\text { The natural logarithm of year-end total assets } \\
\text { revenue divided by Total R \& D expenditure }\end{array}$ \\
& Firm age & LNAGE & $\begin{array}{l}\text { The natural logarithm of the number of years since the } \\
\text { inception of the organization } \\
\text { Dummy variable, which equals } 1 \text { if a firm is an SOE and 0 } \\
\text { otherwise }\end{array}$ \\
\hline \hline
\end{tabular}

\subsection{Sample Selection and Data Description}

The empirical investigation is based on a sample of A-share companies listed on Shanghai and Shenzhen Stock exchange from 2012 and 2015. The sample is selected from the following companies: (1)We select hightech manufacturing and high-tech service industry samples according to the "High-tech industry statistics catalog" revised in 2012; (2)In the samples, companies belong to ST(Special treatment), PT(Particular Transfer) class are excluded; (3)We remove companies with missing data. In the end, we get 1460 samples from 367 listed companies. All financial data were obtained from the China Securities Regulatory Commission web site, the media disclosure of the company's annual report from Juchao and Hexun website, the China Stock Market and Accounting Research (CSMAR) and Flush database.

\section{Empirical Results and Analysis}

\subsection{Summary Statistics of Variables}

For the study, we use the balanced panel data to conduct the statistical analysis by Stata12.0. Table II reports the summary of all variables. We can see that (1) in the implementation process. Chinese management accounting is focusing on formal control. The mean value of formal control (mean=0.288) is larger than the informal control (mean=0.023). (2)Informal control $(\max =0.3824, \min =0.0052$, mean $=0.023)$ in Chinese enterprises exists. We tentatively validate the hypothesis 1 in this paper, which provide a good condition for our follow-up study. 
TABLE II: Summary Statistics

\begin{tabular}{cccccc}
\hline \hline Variable & $\mathrm{N}$ & Min & Max & Mean & Std \\
\hline ROA & 1460 & -15.9301 & 28.8833 & 6.618 & 6.875 \\
IC & 1460 & 0.0052 & 0.3824 & 0.103 & 0.068 \\
FC & 1460 & 0.1013 & 0.5788 & 0.288 & 0.0965 \\
SIZE & 1460 & 19.2878 & 25.081 & 21.841 & 1.047 \\
RD & 1460 & 0 & 33.98 & 5.783 & 5.664 \\
LNAGE & 1460 & 1.7918 & 3.4658 & 2.768 & 0.304 \\
LEV & 1460 & 4.4621 & 85.0809 & 36.982 & 19.202 \\
SOE & 1460 & 0 & 1 & 0.370 & 0.483 \\
\hline \hline
\end{tabular}

\subsection{Multiple Regression Analysis}

Table III shows the regression results for the effect of matching between Formal and Informal Controls on firm performance. According to the different matching types, the samples were divided into four groups. Models 1-4 represent complementary match I ,complementary match II, supplementary match I and supplementary match II respectively. The models 1a-4a test the correlation coefficient of each control variable because each group has different sample number. The coefficient of coincidence of supplementary match $\mathrm{I}$ in model $1 \mathrm{~b}$ is 0.557 , which is significant at $1 \%$ level. The coefficient of complementary match $I$ in model $2 b$ is 0.0613 , which is significant at the level of $1 \%$. The coefficient of coincidence of supplementary match II in model $3 \mathrm{~b}$ is 0.0348 , which is significant at $1 \%$ level. The coefficient of complementary match II in model $4 \mathrm{~b}$ is not significant. Therefore, there are differences among the different matching types of formal and informal controls on firm performance. Complementary match I ,supplementary match I and supplementary match II demonstrate the previous view that informal control has a positive effect on firm performance except formal control. In addition, the interactions between informal and formal controls have a positive and significant effect on firm performance. That is, when formal and informal controls exist in the same enterprise, they are more conducive to improving firm performance. These conclusions verify the hypothesis $3 \mathrm{a}, 3 \mathrm{~b}$ and $3 \mathrm{c}$. But the result of complementary match II is not significant. Hypothesis $3 \mathrm{~d}$ is not validated. It shows that this matching type is not conducive to improving firm performance. It verifies the above analysis that is an effective match.

Further analysis: (1)Complementary match I can not only make both control mechanisms demonstrate their more superior functions, but also get the optimal management accounting income. Executive capability is the dominant function of the formal control. For informal control, adaptive capability is its dominant function. In these circumstances, the formal and informal controls display their dominant function. Management accounting shows a dual-functional perspective (executive and adaptive capability) through the co-ordination of control tools. In that case, informal control can compensate for the acts that they are not emphasized by formal control. We call it "complementary match I".The discrete changes of formal control (the rapid changes) will make the adjustment process of formal and informal controls too intense. The continuous change of Informal control will alleviate this problem [12]. Formal and informal controls have the ability to implement the dualistic strategy [13] .They also effect the exploitation and exploration of organizational duality. The entire control mechanism has both executive capability and adaptable capability. Therefore, if firms want to get the dual functions of executive and adaptive capability, we could conclude that the relationship between formal and informal control is compensatory match I . Compensatory match I will produce a dynamic tension between formal and informal controls. The tension dynamically affects the employee behavior and acts on firm performance. (2) Supplementary match makes formal and informal controls only show a common function (but not necessarily their dominant function). Management accounting shows a single functional perspective (executive ability or adaptability) through the match of control tools. It received a single income. If both the formal and informal controls focused on executive capability, they are limited to immediate benefits and short-term performance of the organization. In the long run, informal control has more influence than formal control. Culture is 
accumulated by organizational members in a long-term process. Once it is formed, it will guide the values and behavioral norms of employees and even the firms' future strategic direction.

TABLE III: Effects of Different Matching Types

\begin{tabular}{|c|c|c|c|c|c|c|c|c|}
\hline Variable & model 1a & model $1 b$ & model $2 \mathrm{a}$ & model $2 b$ & model 3a & model $3 b$ & model $4 \mathrm{a}$ & model $4 \mathrm{~b}$ \\
\hline \multirow{2}{*}{ S } & $1.960^{* * * * *}$ & $2.099^{* * * * *}$ & $2.278^{* * * * *}$ & $2.630^{* * * *}$ & $2.727^{* * * *}$ & $2.798^{* * * * *}$ & -0.240 & -0.0203 \\
\hline & $(7.66)$ & $(8.52)$ & (3.82) & $(4.83)$ & (4.2) & $(4.25)$ & $(-0.35)$ & $(-0.03)$ \\
\hline \multirow{2}{*}{$\mathrm{RD}$} & $-0.154^{* * *}$ & $-0.146^{* * *}$ & $-0.129^{\text {**** }}$ & $-0.070^{* * * *}$ & $-0.0386^{* *}$ & $-0.028^{* *}$ & -0.0782 & -0.0361 \\
\hline & $(-3.29)$ & $(-4.22)$ & $(-5.23)$ & $(-5.70)$ & $(2.51)$ & $(2.36)$ & $(-1.07)$ & $(-0.38)$ \\
\hline \multirow{2}{*}{ AGE } & $-1.298^{*}$ & $-1.260^{*}$ & $-2.118^{* * *}$ & $-3.014^{* *}$ & $-1.138^{* * *}$ & $-0.803^{\text {*** }}$ & 0.756 & 1.905 \\
\hline & $(-2.00)$ & $(-1.97)$ & $(-2.17)$ & $(-1.98)$ & $(-2.12)$ & $(-2.51)$ & $(0.30)$ & $(0.65)$ \\
\hline \multirow{2}{*}{ LEV } & $-0.115^{* * *}$ & $-0.113^{* * *}$ & $-0.153^{* * *}$ & $-0.126^{* * *}$ & $-0.103^{* *}$ & $-0.106^{* * *}$ & $-0.136^{* * *}$ & $-0.140^{* * *}$ \\
\hline & $(-8.7)$ & $(-8.75)$ & $(-4.03)$ & $(-3.91)$ & $(-3.18)$ & $(-3.26)$ & $(-2.41)$ & $(-2.49)$ \\
\hline \multirow{2}{*}{ SOE } & $-1.893^{* * * *}$ & $-2.244^{* * * *}$ & $-1.654^{* * * *}$ & $-2.034^{* * *}$ & $-1.596^{* * * *}$ & $-1.841^{* * * *}$ & -1.812 & -1.790 \\
\hline & $(-4.65)$ & $(-5.34)$ & $(-7.70)$ & $(-6.13)$ & $(-2.89)$ & $(-2.83)$ & $(-1.33)$ & $(-1.32)$ \\
\hline \multirow{2}{*}{ IC } & & $0.0984^{* * *}$ & & $0.0863^{* * *}$ & & $0.0362^{* * * *}$ & & 0.205 \\
\hline & & $(5.62)$ & & $(5.00)$ & & (2.87) & & $(0.07)$ \\
\hline \multirow{2}{*}{$\mathrm{FC}$} & & $0.0435^{* * * *}$ & & $0.0284^{* * * *}$ & & $0.0892^{* * * *}$ & & 0.389 \\
\hline & & (3.59) & & (2.66) & & $(5.00)$ & & $(-1.31)$ \\
\hline supplementary & & $0.0557^{* * * *}$ & & & & & & \\
\hline fit I & & (4.62) & & & & & & \\
\hline complementary & & & & $0.0613^{* * *}$ & & & & \\
\hline fit I & & & & (4.27) & & & & \\
\hline supplementary & & & & & & $0.0348^{* * * *}$ & & \\
\hline fit II & & & & & & (4.84) & & \\
\hline complementary & & & & & & & & -0.0868 \\
\hline fit II & & & & & & & & $(0.67)$ \\
\hline year & control & control & control & control & control & control & control & control \\
\hline & $-2.692^{* * *}$ & $-3.154^{* * *}$ & $-3.011^{* *}$ & $-3.941^{* * * *}$ & $-4.575^{* * *}$ & $-4.900^{* * * *}$ & 1.844 & 4.563 \\
\hline constant & $(-4.74)$ & $(-5.73)$ & $(-2.42)$ & $(-3.20)$ & $(-3.03)$ & $(-3.35)$ & $(1.45)$ & $(0.62)$ \\
\hline$R^{2}$ & 0.1445 & 0.1715 & 0.2032 & 0.2745 & 0.1718 & 0.1871 & 0.2276 & 0.2608 \\
\hline $\mathrm{F}$ & $2.709^{* * *}$ & $2.911^{* * * *}$ & $5.98^{* * * *}$ & $7.81^{* * * *}$ & $6.28^{* * * *}$ & $7.34^{* * * *}$ & $5.67^{* * * *}$ & $5.11 * * *$ \\
\hline $\mathrm{N}$ & 1027 & 1027 & 181 & 181 & 189 & 189 & 63 & 63 \\
\hline
\end{tabular}

\section{Conclusion}

For the study, we use the objective data of Chinese high-tech enterprises to study the relationship between formal control and informal control of management accounting. The results show that: Different matching types of formal and informal controls have different impacts on firm performance. Complementary match I ,supplementary match I and supplementary match II have the positive significant impact on firm performance. While the complementary match II is irrelevant to firm performance.

\section{References}

[1] Okamoto, Kazue, and Stephen TT Teo, "Forms of informal management controls in overseas Japanese companies: A qualitative study,” Employment Relations Record, vol. 9, pp. 64-78, Jan 2009.

[2] Drazin, Robert, and Andrew H. Van de Ven, "Alternative forms of fit in contingency theory," Administrative science quarterly, vol. 4, pp. 514-539, Jun 1985.

[3] Soda, Giuseppe, and Akbar Zaheer, "A network perspective on organizational architecture: performance effects of the interplay of formal and informal organization," Strategic Management Journal, vol. 33, pp. 751-771,Jun 2012.

[4] Gordon, Lawrence A., and Katherine J. Silvester, "Stock market reactions to activity-based costing adoptions," Journal of Accounting and Public Policy, vol. 18, pp. 229-251, Mar 1999.

[5] Cardinal, Laura B., Sim B. Sitkin, and Chris P. Long. “A configurational theory of control,” in Organizational control, S. Cambridge, U.K.: Cambridge University Press,2010,ch5,pp.:51-79.

[6] Tiwana, Amrit, "Systems development ambidexterity: explaining the complementary and substitutive roles of formal and informal controls," Journal of Management Information Systems, vol. 27, pp. 87-126,Feb 2010. 
[7] Ahrens T, and Chapman C S. "Accounting for flexibility and efficiency: A field study of management control systems in a restaurant chain," Contemporary accounting research, vol. 21, pp. 271-301, Feb 2004.

[8] Muchinsky P M and Monahan C J. "What is person-environment congruence? Supplementary versus complementary models of fit,"Journal of vocational behavior, vol. 31, pp. 268-277, Mar 1987.

[9] Uotila J, Maula M, Keil T, et al. "Exploration, exploitation, and financial performance: analysis of S\&P 500 corporations,"Strategic Management Journal, vol. 30, pp. 221-231, Feb 2009.

[10] Sun Q and Tong W H S. "China share issue privatization: the extent of its success," Journal of financial economics, vol. 70, pp. 183-222, Feb 2003.

[11] Rongrui Du and Zezhong Xiao,"The determinants and performance effects of management accounting and controls in listed Chinese firms,"Accounting Research, vol.39, pp.39-46,Sep 2008.

[12] Nickerson J A and Zenger T R. "Being efficiently fickle: A dynamic theory of organizational choice," Organization Science, vol. 13, pp.547-566, May 2002.

[13] Fang C, Lee J and Schilling M A. "Balancing exploration and exploitation through structural design: The isolation of subgroups and organizational learning," Organization Science, vol. 21, pp. 625-642, Mar 2010. 